This item was submitted to Loughborough's Research Repository by the author.

Items in Figshare are protected by copyright, with all rights reserved, unless otherwise indicated.

\title{
When family social capital is too much of a good thing
}

PLEASE CITE THE PUBLISHED VERSION

https://doi.org/10.1016/j.jfbs.2019.01.001

PUBLISHER

(C) Elsevier

VERSION

AM (Accepted Manuscript)

PUBLISHER STATEMENT

This paper was accepted for publication in the journal Journal of Family Business Strategy and the definitive published version is available at https://doi.org/10.1016/j.jfbs.2019.01.001.

LICENCE

CC BY-NC-ND 4.0

\section{REPOSITORY RECORD}

Herrero, Ines, and Mathew Hughes. 2019. "When Family Social Capital Is Too Much of a Good Thing”. figshare. https://hdl.handle.net/2134/36657. 


\title{
WHEN FAMILY SOCIAL CAPITAL IS TOO MUCH OF A GOOD THING
}

\author{
Inés Herrero \\ Universidad Pablo de Olavide \\ Business Management Department \\ Ctra. de Utrera, km 1. 41013 \\ Sevilla \\ Spain \\ Tel.: +34954348906 \\ E-mail: ihercha@upo.es
}

\section{Mathew Hughes (corresponding author)}

Loughborough University

School of Business and Economics

Loughborough

Leicestershire LE11 3TU

United Kingdom

Tel.: +44 (0)1509 223263

E-mail: m.hughes2@lboro.ac.uk

Acknowledgements: This work has been financed by the Ministry of Economy and Competence of Spain through Project ECO2016-75047-P. We offer our sincere thanks to Torsten Pieper, Joe Astrachan, and our anonymous reviewers for their insightful comments and contributions in the development of this paper 


\title{
WHEN FAMILY SOCIAL CAPITAL IS TOO MUCH OF A GOOD THING
}

\begin{abstract}
Family social capital (FSC) is theoretically predicted to benefit family firm performance, but empirical results repeatedly disappoint this expectation. To bridge the disconnect between theory and empirical evidence, we conceptualize FSC as a multidimensional construct in which its dimensions exhibit a mix of positive and negative consequences resulting in a 'too much of a good thing' effect. At high levels, the structural dimension of FSC can cause the family firm to form a structured group and become trapped in its established networks, preventing new knowledge from entering the family firm. With a hand-collected dataset, we test a curvilinear relationship between the structural dimension of FSC and family firm financial performance, and linear effects from its relational and cognitive dimensions. We further examine whether possessing organizational social capital (OSC) mitigates the negative consequences of high FSC. We reveal that the form and combination of FSC matters more than its amount. We contribute to theory a co-dependent view of FSC and OSC (as two different social capitals) that appreciates their concurrent effects.
\end{abstract}

Keywords: Social Capital, Family Social Capital, Family firms, Networks, Family Functioning, Boundary Spanning, curvilinear relationships

\section{HIGHLIGHTS}

- Brings construct clarity to family social capital (FSC).

- Provides a vital reexamination of the theoretical assumptions of family social capital.

- Provides a much-needed empirical test of a multidimensional model of family social capital.

- Structural dimension of FSC exhibits a 'too much of a good thing' effect on family firm financial performance.

- Organizational social capital (OSC) moderates the effect of the structural dimension of family social capital.

- The form and combination of FSC matters more than just its amount.

- Contributes a co-dependent view of FSC and OSC to family business theorizing. 


\section{INTRODUCTION}

Social capital is the sum of the actual and potential resources embedded within, available through, and derived from the social network held by an individual, group, or organization (Nahapiet and Ghoshal, 1998). Access to socially-embedded resources can transform the system of constraints faced by an entrepreneurial firm, particularly around attracting new resources and upgrading its intellectual capital (Cai, Hughes, and Yin, 2014; Stam and Elfring, 2008). Family firms are unique because they possess not only organizational social capital (like any other firm) but also family social capital (Arregle, Hitt, Sirmon, and Very, 2007). Yet, to date, family social capital struggles for construct clarity and our understanding of how it affects family firm performance is driven heavily by normative assumptions. In this study, we seek to provide clarity to the family social capital construct (Suddaby, 2010) ${ }^{1}$ and test the hypothesis that family social capital can represent 'too much of a good thing' to improve the parsimony, generalizability, and accuracy of family social capital theory (Pierce and Aguinis, 2013). We are driven by the question, 'Does more family social capital in a family firm yield a greater level of family firm performance?' This question is vital to answer because family businesses are uniquely placed to build family social capital but are also uniquely placed to rely exclusively on it. That reliance may be the undoing of the family firm.

The family social capital (FSC) construct is often used without precise definition (Danes and Stafford, 2011). However, Arregle et al. (2007) define FSC as an internal "bonding" type of social capital that derives from relationships among family members inside the family firm. Such bonding capital focuses on the linkages among individuals within the collectivity (i.e., the family) (Adler and Kwon, 2002), is characterized by cohesiveness (Nahapiet and Ghoshal, 1998), and is composed of three dimensions (structural, relational, and cognitive) (Carr et al., 2011). However, family firms also possess organizational social capital (OSC) (Zahra, 2010), which results from family firms' interactions, communications, and relationships with diverse stakeholders outside the boundaries of the family firm

\footnotetext{
${ }^{1}$ We define "construct clarity" as put forward by Suddaby (2010) as deficiencies in the scope, boundary conditions, and relationships between social capital constructs as they pertain to family firms.
} 
(Zahra, 2010). Organizational social capital serves as an important relational capital that makes it possible to obtain resources from other companies (Hitt et al., 2002), facilitate internal coordination (Sirmon et al., 2007), and better recognize new opportunities (Adler and Kwon, 2002). Family firms' OSC is a unidimensional construct (Zahra, 2010) and refers to the "bridging" type of social capital that derives from the relationships between the family firm and those outside the family firm.

Since its introduction, research into the effects of FSC remains scarce and most studies have developed solely at the theoretical level (Arregle et al., 2007; Hoffman et al., 2006). Scholars have repeatedly appealed for studies to empirically test its theoretical assumptions and offer evidence for its credibility (Arregle et al., 2007; Zamudio, Anokhin, and Kellermanns, 2014). While holding considerable promise in theory to advance family firm performance (Arregle et al., 2007; Hoffman et al., 2006; Sorenson and Bierman, 2009), empirical studies to date have offered disappointing results. For example, Chrisman et al. (2009) found no significant coefficients, while Carr et al. (2011) could not provide conclusive evidence for its positive effects on firm performance either. A theoretical explanation is that high levels of FSC results in negative outcomes for the firm. Its effects may also be nuanced, requiring a multidimensional treatment of FSC to appreciate the nature of its effects (if any) on firm performance. For example, in constructing a measurement system for FSC, Carr et al. (2011) recognize the multidimensional nature of FSC but treat it solely as a unidimensional construct thereafter. Arregle et al. (2007) also imply such multidimensional features, raising ideas of closure (structure), trust (relational), and moral behavior (cognitive), but without treating FSC as bearing dimensions. Another explanation, as Carr et al. (2011) state among the limitations of their study, is that OSC acts as an overlooked interaction variable because family firms with greater stocks of external ties are in a better position to bring a wider knowledge base to bear on their business activities (see also Chirico and Salvato, 2008; Zamudio et al., 2014). For these reasons, we suggest that theoretical development about FSC to date is incomplete, and in this study we examine the effects of FSC on family firm financial performance (measured by return on equity) and the moderating effects of OSC on the FSC-performance relationship. 
We suspect that FSC exhibits what Pierce and Aguinis (2013) describe as the 'too much of a good thing effect' (TMGT effect). Theory development among studies of FSC has continued to emphasize the benefits of FSC for firm outcomes (Long, 2011) despite disappointing empirical results. Yet, Arregle et al. (2007) warned that the benefits of FSC are potentially too good to be true. Drawing on concerns by Adler and Kwon (2002), Leana and Van Buren (1999), Nahapiet and Ghoshal (1998), Portes (1998), and Uzzi (1996), strong FSC can cause at least three problems for family firms: (1) it risks developing too much social capital and so evoke costs and dysfunctional effects to do with ignoring new information and impeding innovation; (2) it may cause the transfer of dysfunctional family characteristics into the family firm's wider network of relationships, which would impede new information from entering the firm; and (3) FSC may restrict OSC causing organizational advantages to vanish. These concerns suggest a tipping point, reflective of the TMGT effect, beyond which FSC harms family firm financial performance. The absence of such a test represents an important gulf between theory and empirical treatment to date.

Poor construct clarity compounds this problem (Suddaby, 2010). Poor construct clarity has led to an inadequate specification of the variables in the relationship between family social capital and family firm financial performance and the contingencies at play in this relationship. This important omission calls for further detailed theorization of the social capital-family firm performance relationship. We hypothesize an inverted-U shaped relationship between FSC and performance in which FSC has a positive impact on performance for low/medium levels of FSC but becomes negative at relatively high levels. However, we expect that OSC moderates this relationship.

With a unique hand-collected dataset of family firms in the food manufacturing sector, our study offers two important new contributions to knowledge in the family firm literature. First, we contribute to FSC theory by providing arguments to maintain that high FSC can produce dysfunctional effects and we support that theory with empirical evidence. This contribution is enhanced by our multidimensional treatment of FSC and is the first study to reveal how low/high levels of FSC dimensions affect family firm financial performance, evidencing a TMGT effect. Second, our theoretical framing also contributes to a more accurate theorization of this problem. It is not only the amount of FSC that matters but its form 
and combination. Theoretically and empirically we show that the structural dimension of FSC can have dysfunctional effects on family firm financial performance but this can be offset by OSC. Our insights contribute to social capital theory a co-dependent view of FSC and OSC (as two different social capitals) that also appreciates their individual relevance and contribution to organizational advantage. These two contributions bring clarity to the construct of FSC, empirical evidence of its effects, and reveal the implications of OSC for FSC.

\section{THEORETICAL FRAMEWORK AND HYPOTHESES}

\subsection{Family Social Capital and its Effects}

\subsubsection{Literature Review}

Social capital represents the relationships between individuals and organizations that facilitate action capable of creating value (Adler and Kwon, 2002; Arregle et al., 2007) and consists of structural, relational, and cognitive dimensions (Nahapiet and Ghoshal, 1998). We take the position that family social capital is a multidimensional construct in which each dimension may bear unique effects on family firm performance. The structural dimension of social capital reflects the patterns and strength of ties within the members of a group and set the magnitude of the interaction and communication of information; the relational dimension represents the degree of commitment, trust, and identity; and the cognitive dimension represent shared representations, interpretations, purpose, and meaning (Carr et al., 2011; Hughes et al., 2014; Nahapiet and Ghoshal, 1998; Pearson et al., 2008). We adopt this conceptualization for two reasons. First, despite recognition (e.g., Carr et al., 2011) and conceptualization (e.g., Pearson et al., 2008) of its multidimensional form in the family firm literature, FSC has been empirically examined as unidimensional. The empirical effects of FSC have hitherto been conflicting and disappointing, which suggests that FSC has a broader and more complex system of effects that can be appreciated by unpacking FSC. Second, treating family social capital as bearing structural, relational, and cognitive dimensions recognizes their potential to vary independently and to have independent effects on family firm performance. A unidimensional approach takes the position that effects are interdependent but 
in doing so, omit consideration of whether the magnitude of any effect varies independently. This deficit is problematic because, for example, high levels of tie strength are associated with network closure (Adler and Kwon, 2002). Such closure has the potential to harm firm performance by reducing the novelty of information entering the firm. Also, trust is imperative in the relational endeavors of family firms and the degree to which any information originating from a network is used to for strategic decision-making (Cesinger et al., 2016). These nuances are lost without a multidimensional conceptualization of FSC such that a test of its performance effects will mask where performance is augmented or compromised without a multidimensional view of FSC.

From the wider literature on social capital, a large body of research expects that more social capital is better than less (Leana and Van Buren, 1999). Social capital has been assumed to influence knowledge transfers (Hansen, 1999), firm innovativeness (Ahuja, 2000; Tsai, 2001), and firm performance (Nahapiet and Ghoshal, 1998) by upgrading intellectual capital and resource stocks available to a firm. Analogously, authors recognize that family social capital can provide benefits for family firms (Chrisman et al., 2009). The relationships that family members hold with each other can form a special type of social capital, family social capital, which can be used for business purposes (Carr et al., 2011; Sorenson and Bierman, 2009). Family social capital is said to provide family firms with advantages and resources that derive from moral behavior, cooperation, collaboration, and reciprocity among family members. These benefits cannot be easily replicated or substituted by other firms (Arregle et al., 2007). Family social capital is also said to facilitate knowledge integration (Chirico and Salvato, 2008) and support family identity that, in principle, provide further benefits to these firms from the greater cohesion that FSC breeds. However, the resources and advantages that can derive from FSC can also transform into liabilities when FSC is relatively high.

We argue that family social capital is not free of drawbacks and carries potentially negative consequences known as the liability role of social capital (Adler and Kwon, 2002; Leana and Van Buren, 1999; Pearson et al., 2008). Overpowering FSC can be expected to have negative effects that carry the potential to diminish its aforementioned benefits. Arregle et al. (2007) suggest at least three negative 
consequences associated with a strong FSC: (1) an excess of social capital, (2) family conflict interfering with work, and (3) FSC dominating OSC. Excess social capital can create network closure that renders family members close-minded to new ideas (Adler and Kwon, 2002); powerful internal solidarity may trigger inertia to existing courses of actions and worldviews due to the close-knit and protective nature of families (Portes, 1998); the transfer of dysfunctional family characteristics into FSC and OSC (Arregle et al., 2007); and the suppression of OSC as a collective result. However, whether these effects stem from all or only specific dimensions of FSC are yet to be determined. Consistent with our multidimensional view of FSC, we expect the dimensions of FSC to have positive and perhaps negative effects unique to their characteristics, commensurate with the idea that FSC will exhibit a "too much of a good thing effect". We now move to formalize these hypotheses.

\subsubsection{Development of Hypotheses 1-3: The Dimensions of FSC and Family Firm Performance}

Family firms can create a much denser social capital that is difficult to replicate in a nonfamily context (Pearson et al., 2008) because, "the relationships among family members create an ideal environment in which to create social capital" (Arregle et al., 2007, p.76; Bubolz, 2001; Coleman, 1988). While it seems intuitive that nonfamily firms have no FSC, Arregle et al. (2007) specify that, "a 'family owned and family managed' firm with a weak FSC is likely to be more similar to a non-family firm than to a family firm with strong FSC" (p.86). Thus, at low levels, few benefits are likely from FSC. At moderate levels, the performance advantages associated with FSC should surface and grow. However, because the antecedent conditions for dense and relatively high FSC to form are seemingly replete in family firms, there is a much greater risk of the dysfunction effects associated with social capital (in general) and FSC (in particular) taking hold, diminishing the gains that may otherwise occur. Nevertheless, the problems associated with density are unique to the structural dimension of social capital and not its relational or cognitive components. For this reason, we expect that the performance consequences of FSC will differ because of the character of its dimensions, necessitating a multidimensional treatment. 
FSC can facilitate external knowledge sharing and knowledge integration (Chirico and Salvato, 2008), particularly when trustful conditions are in place. Family firms bearing high commitment, identity, or shared values commensurate with the relational and cognitive dimensions of FSC are more likely to obtain valuable resources and knowledge from their ties (Chrisman et al., 2009; Sirmon and Hitt, 2003). Groups without such strong features, however, are less keen on sharing their knowledge (Nahapiet and Ghoshal, 1998). A moral infrastructure of norms, obligations, and expectations underpins a strong cognitive dimension of FSC (Sorenson \& Bierman, 2009; Sorenson et al., 2009). Because of this, Patel and Fiet (2011) maintain that family members with a strong identity and cognitive cohesion use a common language that makes them better at sharing knowledge and combining their knowledge with that from external sources, providing them with "combinative capabilities". These same circumstances afford a degree of residual trust among family members (Long, 2011). The family quality allows trustful relations to build rapidly as an attribute of FSC for business use (Hoffman et al., 2006, Sorenson \& Bierman, 2009).

This collective reasoning is likely to hold through relatively high values of the relational and cognitive dimensions of FSC. We maintain that FSC provides the firm with resource and knowledge advantages particularly to do with the relational and cognitive dimensions of FSC. We expect family members' commitment, identity, and with cognitive cohesion to lead to higher knowledge integration abilities and ultimately to superior family firm performance. Thus:

H1: There is a positive relationship between the relational dimension of FSC and family firm financial performance.

H2: There is a positive relationship between the cognitive dimension of FSC and family firm financial performance.

However, this collective reasoning is unlikely to hold for relatively high levels of the structural dimension of FSC. For example, members of family firms have a rich history or heritage because family members are part of the family since birth. For this reason, they can form strong social ties (Pearson et al., 2008). 
Altruism further increases interdependence and interactions among family members (Patel and Fiet, 2011), achieving relatively strong ties, such that family firms are likely to possess a strong structural dimension of FSC. This condition is likely to yield only redundant and low value information (Adler and Kwon, 2002; Granovetter, 1973; Leana and Van Buren, 1999). Conditions of network closure are exacerbated at these levels. For example, intense ties among family members (high structural dimension of FSC) increases closure (Arregle et al., 2007; Nahapiet and Ghoshal, 1998; Pearson et al., 2008), which diminishes the value and novelty of knowledge obtained through FSC ties and places boundaries around the family firm's network of relationships and constrain its ability to appropriate rents. Family networks often exhibit strong closure as the family institution itself serves as a boundary to the network (Arregle et al., 2007). While a certain amount of closure is needed to develop valuable social capital (e.g., to support common norms, beliefs, trust, and sense of identity) (Nahapiet and Ghoshal, 1998), when a family network is too intense, solidarity among family members can over-embed these members preventing new ideas and information from entering the network (Adler and Kwon, 2002; Coleman, 1990; Leana and Van Buren, 1999; Pearson et al., 2008). Powell and Smith-Doerr (1994) expressed this as "the ties that bind may also turn into ties that blind"' (p. 393). These events occur under conditions of high network density commensurate with high levels of the structural dimension of FSC, and reduce its ability to contribute to family firm financial performance.

There are limitations to the structural dimension of FSC, therefore. When the strength of the family ties reaches relatively high levels, we expect that some of its resources are transformed into liabilities. For example, while the relational and cognitive dimensions of FSC provides family firms with higher knowledge integration abilities, high levels of the structural dimension of FSC makes them reluctant to accept new ideas and hinders their integration. Strong ties favor family identity and the commitment of family members which can lead to performance increases. But at high levels it increases insularity and closure that diminish the sort of rewards associated with FSC. Ultimately, we expect that increasing the strength of the ties will improve firm performance up until high levels of strength, at which a curvilinear effect will follow as the density and closure of the family network causes family members to block 
external influences (and external knowledge) causing performance to decrease. Thus, we hypothesize that the relationship between the structural dimension of FSC and family firm performance is curvilinear and inverted-U shaped:

H3: The relationship between the structural dimension of FSC and family firm financial performance is curvilinear (inverted-U shaped).

\subsection{Development of Hypothesis 4: Family Social Capital and OSC}

FSC represents social capital developed among family members internally within the family firm. However, family firms also rely on ties developed with external individuals and organizations. This is a separate body of social capital termed OSC. Family firms are different from their nonfamily counterparts with scholars drawing specific attention to the family social system (Habbershon, Williams, and MacMillan, 2003). This extends to their external relationships (Chrisman et al., 2009). We argue that the FSC is stronger and unique compared to its OSC. This is consistent with Pearson et al.'s (2008) positioning of FSC as a component of "familiness", but differs from Arregle et al. (2007) who foresaw FSC as input to OSC. Consistent with our treatment of FSC and OSC as the actual and potential resources embedded within, available through, and derived from specific networks of relationships held by a firm, we see the family firm as holding stocks of types of social capital that can interact with one another. We consider that both FSC and OSC can interact with each other such that different levels of OSC may enhance, buffer, attenuate or otherwise change the effect of FSC on firm performance. However, this interaction is specific to the structural dimension of FSC alone. Specifically, we predict that OSC will moderate the curvilinear effect of the structural dimension of FSC on family firm financial performance, changing the sharpness of the parabola.

Theoretically, we do not expect a moderation effect on the relational and cognitive dimensions of FSC. Based on their definitions, these are properties unique to the body of FSC and the relationships among family members. The level of trust in familial ties (the relational dimension of FSC) is a property of the bonds among family members and is independent of any other ties. Stated differently, that family 
members have trustful bonds is not dependent on nor is it affected by whether the family firm has ties to external individuals and organizations (i.e., a stock of OSC) or not. Similarly, a shared set of values, beliefs, vision and representation (the cognitive dimension of FSC) is native to the family system (Sorenson \& Bierman, 2009) and distinct of whether the family firm has any stock of OSC. The relational and cognitive dimensions are then independent of any other ties and are properties of the FSC alone. For the structural dimension of FSC, however, a family firm cannot build an infinite number of relationships of varying patterns and strength. The cost of doing so is prohibitive and the time and energy to invest in dense, cohesive networks of ties are finite (Hughes and Perrons, 2011). When investing in OSC the number, magnitude, and nature of those external ties require time and investment; the knowledge and resources it accesses are different to the structural dimension of FSC; and OSC can reshape the effects of the structural dimension of FSC by exposing the family firm to new, novel, externally-sourced, and nonredundant knowledge to dampen its negative effects at high levels.

Arregle et al. (2007) argued that many works on social capital theory, perhaps by accident rather than design, implicitly suggest that social capital is a homogenous body held by a firm (Nahapiet and Ghoshal, 1998), its people (Burt, 1999), within teams (Chatman and Flynn, 2001), across different levels (Leana and Van Buren, 1999), or its units (Kostova and Roth, 2003; Tsai, 2001). Arregle et al. (2007) rightly argue that the heterogeneity of FSC and OSC has been overlooked, and they propose ways in which FSC might develop the family firm's OSC. But this path dependence is theoretically problematic. Strong family ties are characterized by frequent, intense, and time-consuming relations, in which closure is particularly high (Hoffman et al., 2006). This does not allow for much space to keep many strong relations with external actors or to keep an open mind that allows new information to enter. It is expected then that the structural dimension of FSC and OSC have effects in combination on family firm performance. Connecting with external organizations and actors is a priority for family firms seeking to achieve profitability and growth (e.g., through exposure to novel, non-redundant knowledge, combating against network closure, and encountering new entrepreneurial opportunities) (Zahra, 2010). 
Organizational social capital acts as bridging capital from the family firm to external resources, and overcome the problems of FSC as bonding social capital.

Larger amounts of OSC can provide access to novel information potentially beneficial to the family firm across low, medium or high values of the structural dimension of FSC. For example, external ties can serve as an advice network in which the ties themselves and the information they provide are novel. The advantage of possessing different types of ties is that they provide a wider variety of resources and knowledge to the firm (Coleman, 1990; Jack, 2005). Particularly for family firms, OSC act as bridging ties that relate the family firm to its community and may reduce the problem of redundant information that may flow among family members when the structural dimension of FSC reaches high levels. Indeed, the wider social capital literature suggests the importance of having a good combination of bridging ties (e.g., OSC) and bonding ties (e.g., FSC) (McEvily and Zaheer, 1999). External organizational interactions permit new and novel information to flow into the family firm (Granovetter, 1973). Moreover, through interaction with other firms, family firms can potentially combine external information with internal information to produce better business decisions and improve business activities (e.g., Molina-Morales and Martínez-Fernández, 2009). Thus, a larger amount of OSC would be expected to raise the performance rewards of the structural dimension of FSC across its low, moderate, and high levels.

However, Jack (2005) maintained that researchers should pay attention to the actual nature and function of the different types of relationships and the cost of building and maintaining greater stocks of FSC and OSC. Family social capital and OSC differ in their nature and source. Family members are believed to possess "combinative capabilities" that facilitate knowledge integration (Patel and Fiet, 2011). However, we argue that this occurs for moderate levels of the structural dimension of FSC only. The family identity that develops through high levels of the structural dimension of FSC sets routines and roles for family members, reciprocity obligations, and norms among family employees that increase reluctance to accept new ideas coming from outside the family circle. In turn, increasing levels of OSC in cases of low or high levels of the structural dimension of FSC is likely to create problems. Under low 
levels of the structural dimension of FSC, the family firm would lack the internal infrastructure for knowledge integration because of dysfunction in the connections among family members. At high levels of the structural dimension of FSC, there is likely to be conflict against new external knowledge because of the inertia caused by the insulated, close-knit, and protective nature of the family group. Those family firms that have become reluctant to accept new ideas due to strong family structures, will take less benefits from external resources than those with moderate levels of the structural dimension of FSC. Other than at moderate levels of the structural dimension of FSC then, the family firm is unlikely to benefit from high OSC sufficiently to offset its costs.

Family firms with moderate levels of the structural dimension of FSC and many external ties should benefit from possessing a substantive body of OSC through the increased scope for knowledge integration. Drawing on Patel and Fiet's (2011, pp. 1185) words, "it is not enough to know more than their competitors. They must have the capacity to combine new (external) information with their existing stock of knowledge". For family firms, we expect that while the relationship between family members' identity, commitment, trust or shared vision with family firm financial performance is independent of the OSC the family firm holds, the relationship of the strength of the family ties (the structural dimension of FSC) with family firm financial performance is affected by the level of OSC. When the OSC is high and the strength of the family ties are moderate, the benefits of the latter are enhanced because in this case family members possess high external information (due to OSC) and high combinability capabilities (derived from an optimal amount of the structural dimension of FSC), which should enhance their effects on family firm financial performance. On the other hand, when family ties are weak, the firm will not possess the abilities and communication channels necessary to integrate knowledge, offsetting the positive effects associated with external ties (e.g., exposure to new resources, knowledge, and ideas). In this case, increasing the level of OSC will only lead to family conflict regarding the balance of the power of both types of ties. But at low numbers of external ties, reflective of low levels of OSC, increasing the structural dimension of FSC will positively affect performance up until the threshold beyond which the negative effects of the structural dimension of FSC will remain. This latter effect is due to the high cost 
associated with maintaining increasing levels of the structural dimension of FSC together with the resistance to accept information coming from outside the family circle and, consequently, the acquisition of new knowledge. Thus:

H4: OSC moderates the relationship between FSC and family firm financial performance. We expect that high OSC will enhance the positive effects of medium levels of the structural dimension of FSC whereas low OSC will mitigate the negative consequences of high FSC on family firm financial performance.

\section{METHODS}

\subsection{Data}

We set our empirical analysis in the food manufacturing sector in Spain. We chose this sector because it is one of the most relevant ones for the Spanish economy, occupying the first place in the revenues of the manufacturing sector and representing nearly $3 \%$ of the Spanish GNP. The food industry is the fourth in Europe in terms of net sales. Employment in this sector represents more than $20 \%$ of the total employment in the industrial sectors. According to the Spanish Ministry of Agriculture, Fishing, Food and Environment (2018) this sector has been one of the industrial sectors that have better endured the recent economic crisis. Not only is food manufacturing a key sector in Spain, but the percentage of family firms within this sector is of high relevance. Furthermore, while the percentage of family firms out of the total is approximately $60 \%$ on average in European countries, this rate is higher in Spain, being around 89\% (Casillas-Bueno, López-Fernández, Meroño-Cerdán, Pons-Vigués, and Baiges-Giménez, 2015). The food manufacturing sector has increased their R\&D efforts in the last few years too, being higher than the average in the manufacturing industry (FIAB Economic Report, 2017). Recently, governments have made strong efforts to promote innovation in this sector by creating new technological centers such as foodforlife (http://foodforlife-spain.es/info/). In this context, the role of social capital is key, as a driver to obtain resources and explicit and tacit knowledge leading to innovation. 
While most existing studies focus on publicly listed firms, we concentrated our study instead on privately held firms. We acquired and combined two different datasets, one from primary sources and one from secondary sources. To enable data collection, first, we acquired a list with all the firms in the food manufacturing sector (CNAE code 10) from the Bureau Van Dijk and Informa (SABI) dataset. SABI is similar to COMPUSTAT and it includes descriptive and financial data. It covers countries such as Spain and has been widely used in research (Cruz, Gomez-Mejía and Becerra, 2010). We filtered data by selecting only those firms that were active and that were operating in the food manufacturing sector using NACE rev. 2 code, obtaining 11,611 firms. We also filtered by those firms that had the telephone number data available. Following Blanco-Mazagatos, Quevedo-Puente and Castrillo (2007) and Chrisman et al. (2009), we eliminated micro firms (based on the EC definition) and we finally considered firms with more than 10 employees. This action avoids relatively small firms to ensure comparability between the firms and to ensure that there are enough family members in the firm to develop social capital. Then, we eliminated those firms with missing economic data, which reduced our population to 3,789 observations. We randomly contacted a group of them and we obtained a response rate of about $10 \%$ from family managers. A response rate around $10 \%$ is not ideal, but it is acceptable and similar to that of other studies in a similar setting and the same country (e.g., Cruz et al., 2010; Claver, Rienda, and Quer, 2009). The number of observations in the final sample totaled 163 firms. While we wanted this number to be higher, reliable social network data are notoriously difficult to obtain, particularly for family firms who tend to be reluctant to share private relational information (Zamudio et al., 2014). Still, the number of observations is similar to or higher than other studies involving network data (Ling and Kellermanns, 2011; MolinaMorales and Martínez-Fernández, 2009) and sufficient for the purposes of our analyses.

A firm was considered a family firm if one family possessed more than $50 \%$ or the firm shares and if the respondent considered the firm to be a family firm (Molly et al., 2010; Sorenson et al., 2009; Westhead and Howorth, 2006). Based on their answers, approximately $60 \%$ of the firms contacted were family businesses. The percentage of family ownership in our sample was on average $98 \%$. On average, they had 40 employees, with 4 family members involved in the business. They were not lone founder 
firms. When analyzing the data, we checked that all the firms in the sample had employees with kin ties to the owner.

We then used direct interviews with a family manager — a member of the owning family that occupies a manager position at the firm. Beforehand, we designed the questionnaires and shared them with three experts as a pre-test. One was a manager at a survey firm, another was an academic with experience in surveys among family firms and the third was a manager of a family firm. Slight modifications were made to the questionnaires as a result of the suggestions provided by these experts. Data were then formally collected through direct interviews with the managers by phone in early 2014 . We aimed at interviewing the firm's CEO, which was in the vast majority of the cases a family member, but when this was not the case it was necessary to interview a family manager (even if not CEO), as, empirical evidence in the literature suggest that a nonfamily CEO is not the appropriate person to answer family issues (Herrero, 2018). Although focusing on owner-managers of these firms may not capture the attitudes of other family members, this choice involved the perspective of the key decision-maker within the family firm (Carney, 2005) and has been used in previous research (Carr et al., 2011). Frequently, we had to contact the same firm on several occasions as, often, the family manager/s could not attend us. Each interview took around 30 minutes, though the length of the duration varied to a great extend from one to another.

In our interview with the managers, they were asked about some firm characteristics such as the family character, number of employees, and number of family employees. We also asked the interviewees questions regarding their firms' level of FSC and OSC according to a specified scale based on existing literature. This represents our second dataset.

\subsection{Measures}

Return on Equity (ROE): The dependent variable we used in our study was the return on equity, calculated as the ratio of EBIT (Earnings Before Interests and Taxes) over Equity. ROE measures a firm's profitability by revealing how much profit a company generates with the money shareholders have 
invested. This is particularly appropriate for family firms because family wealth is directly tied into the wealth of the business (Carney, 2005). ROE is also recognized as an important performance measure for family firms (Adams, Manners, Astrachan and Mazzola, 2004).

Family Social Capital: FSC was measured using the Carr et al. (2011) scale (see Appendix) and we used the factors resulting for each of the dimensions of the factor analysis in the regression analysis. It consists of a 12-item scale ranging from 1 to 5 based on a second-order aggregation of 3 dimensions with 4 items for each dimension (structural, relational and cognitive dimensions). This is one of the few scales that exists in the literature to measure FSC and was formally validated by its authors and subsequent work (Herrero, 2018). The 12-item FSC possessed high reliability, with a Cronbach alpha of 0.934 and a rho coefficient of 0.95 . The three dimensions exhibited Cronbach alpha equal to 0.80 (structural dimension), 0.92 (relational dimension), and 0.89 (cognitive dimension). These results are in line with those of Carr et al (2011). The average values taken by the three dimensions of the FSC were quite high (Table 1), which is in line with other results in previous literature (Carr, Cole, Ring and Blettner, 2011; Herrero, 2018). Even if the reason could potentially be that family managers may tend to inflate these figures, given the data collection method, one would expect that their answers would maintain proportionality given that literature has shown that responses regarding FSC are consistent among different family managers (Herrero, 2018).

Organizational Social Capital (OSC): We included a measure of OSC composed of 5 items developed by Zahra (2010) to account the potential influence of this important form of relational capital. Zahra's (2010) OSC construct is not dimensional in nature, and measures a family firm's OSC as a 5-item index on a 5 -point response format $(1=$ strongly agree vs. $5=$ strongly disagree $)$ in which the 5 items are then summed and averaged to create OSC. The measure, consistent with the construct definition, indicates the belief of the family firm in how other companies might view the family firm. Its items include having a good reputation in its industry, being well connected to other companies in its industry, being well connected to other companies in other industries, having a good reputation for supporting industry causes, 
and having a good reputation for fair dealings. The Cronbach alpha coefficient was 0.833 , higher than that obtained by Zahra (2010), which was 0.75 . The Rho coefficient was 0.837 . Both indexes showed a high reliability.

Controls: We controlled for firm size, measured by the number of employees, as a control variable in our study as it may affect firm performance. To account for seasonality, we followed the European Commission recommendation of May, $6^{\text {th }}, 2003$, that counts seasonal workers as fractions of annual work units. We also considered the number of generations involved in the management of the family business, which has been shown to affect information exchange frequency (Zamudio et al., 2014) and firm results (Gomez-Mejía et al., 2007). We also used the firm's age and family involvement. Regarding family involvement, we used the number of family members involved at any of three levelsownership, management, and employment level—as a measure of family involvement. Family involvement is commonly made up of the number of family members involved in ownership and management, but family employment can also affect the way family firms perform (Birley, 2001). We preferred the absolute term of family involvement rather than their percentage with respect to total amount of employees because the majority of the firms in our sample have their whole stake in the family hands, so the family members likely possess a strong influence regardless the amount of employees. Finally, we have included Family management, which is a dummy variable indicating if the CEO belongs to the owning family (Family management $=1$ ) or not (Family management=0).

\section{RESULTS}

In Table 1 we show the descriptive statistics of our data. On average, the firms in the sample possess 40 employees, and there are more than 4 family members (Table 1) involved in the firm (standard deviation 2.23), of which 2.7 are family employees, and on average 1.3 are family owners (most family owners are also family employees and/or managers). The average number of generations involved in the family business is 1.3 , with a standard deviation of 0.45 (Table 1). Surprisingly, the number of generations in the family business appears not to be significantly correlated with any of the variables, with the only 
exception being the number of family members involved in the business (corr $=0.256)$. ROE is positively correlated with the number of employees, as expected but negatively correlated to family management. It is also positively correlated with the relational dimension of FSC.

\section{INSERT TABLE 1 ABOUT HERE}

Both the FSC and the OSC scales have been previously validated in the literature (Carr et al., 2011; Zahra, 2010). However, due to the still limited number of applications of this measure in the literature and the fact that this context is different, we followed good practice to conducted a confirmatory factor analysis (CFA) using robust estimators (see the Appendix) (Astrachan, Patel, \& Wanzenreid, 2014; Memili, Eddleston, Kellermanns, Zellweger, \& Barnatt, 2010). Results confirmed the three-factor secondorder structure for FSC, in line with the results of Carr et al. (2011) and Herrero (2018). Akaike Information Criteria (AIC) was 4434.497; The Root Mean Square Error of Approximation (RMSEA) was equal to 0.04 and the SRMR (Standardized Root Mean Square Residual) was 0.049, which are both below the maximum acceptable level of 0.08 (Hu and Bentler, 1999). The goodness of fit indices were within acceptable or tolerable levels (Hair, Black, Babin, \& Anderson, 2010): the comparative fit index (CFI) measuring the proportion of total variance that the model explains adjusted by the sample size is equal to 0.95 and the TLI is equal to 0.94 , both being higher than 0.90 for acceptability; all the previous indexes show good fit.

We assessed the convergent validity of our model in three ways (Hair et al., 2010; Memili, Eddleston, Kellermanns, Zellweger, \& Barnett, 2010). First, we checked that all resulting coefficients of the CFA (see the Appendix) were statistically significant and higher than 0.5. Consequently, we can consider that both the second order factor model of FSC and the OSC scale were validated (Appendix). Second, we calculated the Average Variance Extracted (AVE) for our two latent constructs; the average AVE for FSC was 0.65 whereas the average AVE for the OSC was 0.54 , both higher than the minimum 
threshold of 0.5. Finally, we calculated the composite reliability. Composite reliability was 0.88 for FSC and 0.98 for OSC, in both cases it was far from the 0.7 threshold suggested by (Hair et al., 2010).

To test for the discriminant validity of our two key constructs we checked that the average variance extracted (AVE) of FSC and OSC ( 0.65 and 0.54 , respectively) was higher than the correlation between them (0.47) (Hair et al., 2010), supporting discriminant validity.

In Table 2 we present the results of the hierarchical regression analysis. The condition indices (CI) were all lower than 30, suggesting that multicollinearity was not a problem. Regarding control variables, we can observe that firm size has a significant and positive effect on family firm financial performance (represented by ROE). A potential explanation can be found in the debt of these firms. We collected data on firm's debt and observed that bigger firms use more debt (with a high and significant correlation, 0.57 ) and a higher debt level, particularly long-term debt, is also associated to higher ROE (correlation 0.32 ). However, our results show that family management negatively affects family firm performance. The reason for this can again be found in that family managers are more reluctant to get into debts. Indeed, we found that the correlation between the two variables was negative and significant, supporting such idea. Interestingly, we found that the percentage of family employees is also negatively correlated to debt. The remaining control variables were not significant.

From the hypothesis testing results, we conclude that the relational and cognitive dimensions of FSC enhance family firm financial performance, as both coefficients are positive and highly significant. Hypotheses 1 and 2 are therefore supported. The structural dimension of FSC does not have a direct effect on family firm financial performance. However, as predicted, the second-order term of FSC is negative and highly significant, providing partial support for Hypothesis 3 (Table 2, Model 2). Furthermore, given that the linear and quadratic term can be correlated, resulting in erroneous high coefficient it is recommended to check that the R-square increase and the change in the goodness of fit when we add the quadratic term are significant, as occurs in our case (Table 2). To test for an inverted-U shape, we need to test two conditions: that the second order coefficient is negative and that the maximum value of the function is within the range of our function (Lind and Mehlum, 2010). For robustness and following Lind 
and Mehlum (2010), we run a Sasabuchi U test to check for an inverse-U shape. The overall test of presence of an inverse- $U$ shape was significant at the $5 \%$ level (t-value $=1.93$; $p$-value $=0.028)$, supporting our curvilinear hypothesis. Results showed an extreme point at -0.56 , and the $95 \%$ Fieller interval for the maximum was $(-1.07 ; 0.740)$, which is within the range of our variable. It also showed a positive $\left(\mathrm{s}_{1}=\right.$ 1.23) and significant $(\mathrm{p}=0.001)$ slope at a lower bound of the interval around the extreme value and a negative $\left(\mathrm{s}_{\mathrm{u}}=-0.36\right)$ and significant $(\mathrm{p}=0.027)$ slope at the upper bound of the interval around the extreme value, which provides support for a curvilinear inverted-U shape. We can then maintain that the relationship between FSC and family firm financial performance is quadratic and exhibits an inverted-U shape. Similarly, firm performance was standardized, so that it is centered in zero, being able to take negative and positive values around zero. We graphed this relationship in Figure 1. We considered low (high) level of FSC to the mean plus (minus) the standard deviation of the factor associated to the structural dimension of FSC. It is observed that family firm financial performance increases up to a threshold from which increasing the level of the structural dimension of FSC any further leads to decreases in family firm financial performance. These results support a TMGT effect from the structural dimension of FSC on family firm financial performance, so that when family members hold an increasing number of relationships between them, family firm performance increases. However, this relationship suffers from the TMGT effect: There is a threshold at which increasing amounts of relations lead to family members becoming too involved in family relations, impeding other external relations and ideas getting into the family pool of knowledge.

\section{INSERT TABLE 2 AND FIGURE 1 ABOUT HERE}

Somewhat unexpectedly, the results of the hierarchical regression analysis also show that the direct effect of OSC on family firm financial performance is not significant in many of the models considered. However, it has a direct positive effect on family firm financial performance when we 
introduce it as a moderator of the relationship of the structural dimension of FSC and performance. Both the direct and moderator effects are only significant at the $10 \%$ level (Table 2, Model 1), providing only partial support for Hypothesis 4. For a better understanding of this relationship, we represent the interaction effect in Figure 2. We considered high (low) levels of OSC to the mean plus (minus) the standard deviation.

\section{INSERT FIGURE 2 ABOUT HERE}

Firms with medium values of the structural dimension of FSC and with a high OSC perform better than those with low OSC. When the amount of OSC is low, the pattern of the relationship between the structural dimension of FSC-and family firm financial performance is very different, as the quadratic effect is very mild. In this case, there is a positive effect of the structural dimension of FSC on family firm financial performance which hardly ever reaches any threshold point at which family firm financial performance decreases as occurs for those firms with low external ties. Consequently, when firms possess high OSC, the structural dimension of FSC exerts a positive effect, though the impact of the positive effect that increasing further the structural dimension of FSC has on performance is negative. This implies that even if these firms possess high OSC, the high FSC impedes the family firm to extract value from the OSC, showing a lower performance than those firms with medium or lower levels of FSC. These firms are likely narrow minded and are locked into the family relations, showing a TMGT effect. On the other hand, we observe in Figure 2 that the financial performance of isolated family firms increases relatively mildly when the structural dimension of FSC increases and decreases very slightly when it reaches higher levels. From this result, we can deduce that in our case, family firms need a certain level of OSC to leverage the benefits of the structural dimension of FSC.

To check for robustness of our results, we repeated our empirical analysis using self-rated performance as the dependent variable (although for clarity purposes we chose not to display it in the tables provided) and Return on Assets (ROA). Self-rated performance was measured using the scale of 
Acquaah (2012). Managers were asked to assess five measures of performance relative to the major competitors in their industry. These five measures were growth in productivity, growth in sales and revenues, growth in net income/profits, return on assets (ROA), and return on sales (ROS). The five subjective measures are reported to correlate highly with the respective objective measures (Acquaah, 2012). The self-rated performance measure was calculated as the average measure of the five measures just mentioned. Regression results were similar to the previous ones concerning the relational and cognitive dimensions, suggesting that aspects such as trust, commitment, and share visions provide a positive perception regarding the firm's functioning. However, while the curvilinear effect of the structural dimension was not significant, we believe that this suggests that family members may not be able to perceive that very strong relations can harm firm's performance. Furthermore, the effect of the context, a sector that has endured the economic recession better than the rest of the manufacturing sector, may be affecting our results, as family managers may be more optimistic in evaluating their own performance. Similarly, when using ROA as a further test, our key variables were not significant. In fact, ROA and ROE do not measure the same type of performance and, in our case, the results differ to a certain extent. ROE is suggested as one of the most appropriate performance measure for several reasons, including that it takes into account the cost of capital (Adams, Manners, Astrachan, \& Mazzola, 2004). This is in line with other empirical works of family firms, which acknowledge that ROE is affected by family issues but not ROA (see a recent study by Herrero, 2018, or the meta-analysis of O'Boyle et al., 2012).

\section{DISCUSSION AND CONCLUSIONS}

The aims of this work were to (1) bring clarity to the FSC construct by theoretically framing its system of effects at the multidimensional level ${ }^{2},(2)$ correct the disconnection between theory and empirical evidence by theorizing and testing for the 'too much of a good thing' (TMGT) effect (a curvilinear,

${ }^{2}$ The literature recognizes FSC as a multidimensional concept but does not treat it as such. Our results illustrate the differing effects of its dimensions. 
inverted-U shaped effect) resulting from the strength of the structural dimension of FSC on family firm performance, and (3) to understand the contingency effects of OSC as an alternative block of social capital available to family firms on this relationship. Our findings provide timely and important construct clarity to FSC, a vital reexamination of its theoretical assumptions, and a much-needed empirical test that shows the position of the TMGT effect and a moderator of this effect. We offer two contributions to theory on FSC, both with affiliated managerial implications.

Our first contribution provides theoretical arguments and empirical results to support FSC as a multidimensional construct whose dimensions have different consequences for family firm performance. While the definition of FSC indicates a multidimensional construct, its empirical treatment in the literature has so far used a singular construct (Carr et al., 2011). Family social capital has then suffered from ambiguity in its conceptualization (Arregle et al., 2007; Molina-Morales and Martínez-Fernández, 2009). By conceptualizing FSC as multidimensional, we provide the theoretical rationale and empirical evidence that explains why, to date, the credibility of FSC has been called into question (Zamudio et al., 2014). Our treatise explains why the structural dimension in particular may yield curvilinear effects versus the positive direct effects of its relational and cognitive dimensions. This treatment explains the failure of empirical studies to evidence the alleged promise of FSC to advance family firm performance (e.g., Arregle et al., 2007; Hoffman et al., 2006; Sorenson and Bierman, 2009; cf., Carr et al., 2011; Chrisman et al., 2009).

Our theoretical model predicts the capacity of the structural, relational, and cognitive dimensions to make unique and different individual contributions to family firm performance. Our findings suggest that the relational dimension featuring trust and commitment and the cognitive dimension featuring shared identity, share vision, and common goals exert positive effects on family firm financial performance and do not harm performance at relatively high levels. However, our findings show that the structural dimension of FSC has a curvilinear inverted-U shape relationship with family firm financial performance, validating the theoretical concern of a TMGT effect that Pierce and Aguinis (2013) claim is pervasive but largely ignored in theory development, theory testing, and management practice. We 
conclude that while the structural dimension of FSC gives access to readily-available resources to family firms, providing them with benefits regarding knowledge integration, family firms with a relatively high structural dimension of FSC (relatively strong and frequent relationships) can experience 'too much of a good thing' and suffer a decline in financial performance. There are dysfunctional effects to closure in FSC and family ties.

The more intense and the more enduring the structure of relationships among family members, the less likely new information will enter the network (Adler and Kwon, 2002; Arregle et al., 2007; Leana and Van Buren, 1999; Zahra, 2010). This is particularly acute for family firms where strong family ties are linked to strong network closure. However, we caution that our empirical application focuses on just one country and on one particular market segment — the food manufacturing sector in Spain. This has the advantage that the sample is homogeneous, so it is not affected by differences in operations behavior or profitability of different sectors. But, it is potentially affected by other factors, such as the strong family norms in a country like Spain. This fact might bear on our results, as the average levels of the dimensions of FSC are possibly higher in our case than in other settings. Still, redundant information and high closure set resistance to change and provide the basis for why family firms high in the structural dimension of FSC witness diminishing return to family firm financial performance. In any case, this evidence explains why a dichotomous view of FSC as beneficial or costly (e.g., Pearson et al., 2008) masks that its benefits and problems are specific to its dimensions, and not to the overarching concept itself. The liability role of FSC then is limited to its structural dimensions in our findings.

We conclude that the structural dimension of FSC is a double-edged component capable of explaining why too much family social capital can hurt family firm financial performance. Our findings provide a theoretical explanation and set of empirical evidence to reconcile why, despite widely held normative assumptions about FSC leading to desirable returns to family firm performance, actual empirical results have repeatedly disappointed those expectations. Our work brings construct clarity to FSC (Suddaby, 2010) by remedying deficiencies in the form, scope, boundary conditions, and 
relationships of FSC. a multidimensional treatment reveals a TMGT effect, the source of this TMGT effect, and moderators of this effect.

Our second contribution extends emerging evidence of family firms' reliance on OSC beyond FSC alone (Zahra, 2010). Our overarching fear was that a failure to understand the nature of FSC coupled with alternative forms of social capital held by family firms (i.e., OSC as well as FSC) would lead to an erroneous and incomplete understanding of the value and effects of family social capital against organizational social capital for these firms. The literature on the theory of FSC (Arregle et al., 2007) and its contribution to familiness (Pearson et al., 2008) suggest that large amounts of family ties (the structural dimension of FSC) can cause closure, redundancy, and indifference towards new information. Authors have projected the benefits of OSC to family firms, indicating its ability to bring a wider knowledge base to bear on the family's business activities (e.g., Carr et al., 2011; Chirico and Salvato, 2008; Zamudio et al., 2014; Zahra, 2010). We show, however, that the effects are more complicated than this. Because the relational and cognitive dimensions of FSC are unique properties tied to its set of relationships, we predicted that only the structural dimension of FSC is subject to the family firm's OSC because any one firm can only devote so much time and resource investment into a non-infinite number of relationships. In turn, we predicted that varying degrees of OSC could benefit and ameliorate the quadratic relationship between the structural dimension of FSC and family firm financial performance.

We find that OSC moderates the quadratic effect the structural dimension of FSC has on family firm financial performance. Organizational social capital extracts value from the links family firms form with other external networks capable of providing access to new knowledge, which together with the knowledge absorptive capacity that the structural dimension of FSC provides can facilitate performance. We demonstrate empirically that these theoretical expectations hold true and that OSC increases greatly family firm performance for medium levels of the structural dimension of FSC. However, OSC also exacerbates the negative quadratic effect of higher levels of the structural dimension of FSC on family firm financial performance as the latter do not allow the entrance of the benefits of external ties. By revealing the differences between these two categories of social capital theoretically, and demonstrating 
their interrelated effects empirically, we advance theory on FSC but also extend social capital theory itself. Social capital theory has tended to ignore that it is not only the amount of social capital that matters but its form and combination. Theoretically and empirically, we show that the structural dimension of FSC can have dysfunctional effects and that its interaction with OSC alters those effects. This contributes to social capital theory a co-dependent view of FSC and OSC (as two different social capitals) that appreciates their individual relevance and contribution to organizational advantage.

If a firm does not maintain new forms of relationships outside of their family network, the network will come to exhibit redundant knowledge and will lack the different knowledge, abilities, and skills necessary to reach a rich FSC truly valuable to firm performance (Coleman, 1990). Our results show that family firms with low OSC are isolated, do not receive information from external sources, and find themselves with a lack of external resources to enrich their knowledge. Consequently, family firms low in both FSC and OSC are low performers. These firms cannot get the benefits associated with social relations nor the information that comes through them. Interestingly, firms with low FSC and high OSC are also low performers because they cannot benefit from the OSC due to the poor internal relations among family members. Our results show that if family firms possess low OSC, the benefits associated with FSC are relatively mild (Figure 2), if any, and at high levels of FSC the disadvantages surpasses the benefits. Those family firms with high FSC and low OSC tend to be quite isolated, with clear closure boundaries and narrowmindedness which lead them to be relatively low performers. They may suffer the “Not Invented Here" syndrome, which Adler and Kwon (2002) attribute to firms with high internal but low external social capital. Adler and Kwon (2002) suggest this will create a situation in which the solidarity born from strong internal social capital will be detrimental to their integration into external ties. We extend these concerns with insight from family firms that reveal that a high structural dimension of FSC becomes dysfunctional without external ties to provide new information, ideas, and viewpoints. However, we acknowledge that this finding might be specific to our context: the relatively strong family norms in Spain may cause the negative effect of the structural dimension of FSC to be higher due to the high average level of this variable. In other cultural settings, with samples including more firms with 
lower levels of FSC, the positive effect of low-medium levels of this variable may be more patent and the mild effect that this variable exerts for isolated firms could be stronger in other settings.

On the other hand, family firms rich in OSC have access to information which can potentially improve family firm performance. Our empirical results support that family firms with high OSC but low in the structural dimension of FSC obtain benefits from external sources but through weak family norms and values will not benefit from the resources they could obtain if they could better exploit their FSC. Increasing their structural dimension of FSC is positive for these family firms as they obtain the benefits of stronger and more frequent family ties while at the same time having external information available. Family firms with at least moderate amounts of FSC are more likely to obtain valuable resources and knowledge from ties with other external firms (Chrisman et al., 2009; Sirmon and Hitt, 2003) as FSC facilitates the integration of new information with existing ones (Chirico and Salvato, 2008) and because the appropriate strength of these ties facilitate the transfer of tacit knowledge (Levin and Cross, 2004). However, firms would be affected by the negative consequences of possessing a high structural dimension of FSC. Such ties would not allow the benefits of possessing high OSC to appear due to the restrictive character of this dimension of FSC and subsequent conflict in sustaining both types of social capital. In consequence, we can conclude that to increase their profitability, family firms should place emphasis on the development of their FSC, with special care not only on developing trust and cohesion among their family members, but also on the avoidance of relatively dense and frequent family relations that could isolate them from other relations with external actors. Increasing external relations builds valuable OSC.

Our findings draw attention to boundary spanning family members. Our empirical analysis shows that the structural dimension of FSC has dysfunctional effects on family firm financial performance at high levels. But OSC can offset this decline, with moderate levels of family ties being ideal. Family managers must invest in increasing family firms' external relations is to prevent a family orientation lock. To do so, our conclusions point to the usefulness of "boundary spanners" (Tushman \& Scanlan, 1981) and individuals sitting at the "structural fold" between multiple networks (e.g., the family, external businesses, 
partners in industry, or community members) who can facilitate access to diverse resources and bring in needed alternative perspectives (Vedres \& Stark, 2010). Historical (e.g., Tushman \& Scanlan, 1981) and current (e.g., Edmondson \& Harvey, 2018) research place emphasis on boundary spanners as technically competent individuals well-connected internally and externally, operating within and across firms.

Internally, boundary spanners can connect teams of individuals with new knowledge to support innovation (Marrone, 2010). Nonetheless, caution is needed to ensure that the family identity of family members does not lead to connections characterized solely by kinship. Surprisingly, these notions have not yet found much traction in family business but in raising their importance here, we encourage family managers, advisors, and scholars alike to invest time and resources to identify and leverage these boundary spanners to support FSC and OSC efforts.

\subsection{Limitations and Directions for Future Research}

Our study has limitations. First, more work is needed on the potential adverse effects of the dimensions of FSC and moderators of these effects. The possibility that FSC may transfer dysfunctional family properties into OSC is especially intriguing. While we reasoned that relational and cognitive dimensions of social capital are properties unique to the specific set of ties to which that social capital relates (e.g., the family, external organizations, etc.), we did not consider the possibility of internal organizational moderators on the functioning and utility of FSC. Further embedded in our discussion is that the first order inflection point of FSC may move to the left or right depending on the level of family functioning. An indication of this is partially visible in Figure 2 when comparing the slight difference in the apex of the curves under high/low levels of OSC. We observed that family firms with at least moderate amounts of FSC gain more from external ties, in part because moderate or higher values of FSC may support family firms' combinative capabilities. This implies that family functioning is a relevant internal contingency on the FSC-performance relationship, and is worthy of future research.

Second, our context is limited to the food manufacturing industry in Spain. While focusing on just one sector reduces the generality of the results, the results are more accurate as they avoid the interference 
of other variables such as differences in operating system, in industry behavior, or sector profitability that could affect the results. This sector in Spain has some peculiarities that distinguish the setting to that of other countries. In the food manufacturing sector in Spain, there are many small firms competing in the same market and fewer larger firms, whereas in other European countries the number of medium-size firms is higher. However, being one of the most profitable industries in Spain and one of the sectors that better endured the last economic crisis, makes this sector an interesting ground for research. Empirical research studies on sectors beyond food manufacturing would benefit the FSC literature but so would studies that expand on its nomological network. There is a dearth of empirical evidence on FSC, its antecedents, and its consequences, due in no small part to the difficulty of obtaining data. This calls for thought to be given to innovative ways of collecting data, for example through studying configurations (Hughes et al., 2018) and latent profiles (Stanley et al., 2017). Third, measuring family social capital in larger firms would support the generalization of our hypotheses and findings. Also, our sample size compares well to other studies of FSC but even larger samples examined over time would be preferable. Additionally, having observed that FSC levels in this and other previous studies are relatively high, it would be desirable to compare these results with future studies based on other data collection methods, which allow for anonymous answers.

Fourth, we focused only on relationships among family members and external firms. Relationships between the owning family and nonfamily employees as an alternative body of social capital within the family firm may also be important. Good relationships between nonfamily employees and family members may provide knowledge external to the family that, at the same time, resides within the firm. These nonfamily employees could also act as conduits between the family and the larger community, facilitating access to and the integration of new knowledge. Note that a limitation of the Carr et al. (2011) measure is that it limits FSC only to family members who work within the firm itself (see also Arregle et al., 2007). Future studies should consider the support provided by family members not working inside the family business but who can (and do) lend support to the family firm nonetheless. 
We rely on an objective economic measure of family firm performance, ROE. However, the different results that family firm variables have depending on the different performance measures used opens an interesting ground of research. Future research should focus on how different levels of debt and different costs of capital for family and nonfamily firms can affect family firm performance depending on the measures taken. Family firms are more reluctant to incur high debt levels while they tend to be more prone to include family capital into firm's resources in the form of equity. Furthermore, although economic measures of family firm performance are widely used in family firm studies, scholars should look to capture non-financial performance aspects with some of the recently developed scales now at researchers' disposal (e.g., Debicki et al., 2016; Hauck et al., 2016). Many family firms have goals that are socioemotional and not merely financial, and these goals can change strategic behavior or bend their priorities under certain situations (e.g., Cesinger et al., 2016). Family social capital might correlate more highly with family non-economic goals than financial performance. An exciting future line of research, therefore, is to analyze the balance between non-economic and economic goals and its relation to FSC. Family businesses with powerful family relationships, commensurate with high FSC, may enjoy greater familiness, but have more interest in preserving it than families that keep poor relations with problems that distance the family from participation.

\subsection{Conclusion}

This study provides (1) theoretical arguments and (2) empirically evidences of the distinct effects of each of the FSC dimensions on family firm financial performance, and (3) demonstrates how OSC can alter negative quadratic effects resulting from the structural dimension of FSC. We refine current theoretical treatments to show circumstances in which the combination of FSC and OSC may mitigate or accelerate some of the negative consequences of FSC for family firm financial performance. Our work brings timely and important construct clarity to FSC and revises its theoretical assumptions by demonstrating that FSC exhibits the 'too much of a good thing' effect from its structural dimension. In revealing that OSC moderates this effect, we demonstrate the necessity to understand the composition of these two different 
forms of social capital, and not treat social capital as a unified body. Moreover, in demonstrating the broader merits of the relational and cognitive dimensions of FSC, we empirically validate the significance of treating FSC as a multidimensional construct, correcting the tension in which studies have defined FSC as multidimensional but treated it as unidimensional. We advance the theory of FSC by upgrading the ability to predict when FSC in totality may have positive or negative effects overall. In turn, our explanations and empirical evidence provide the basis to reconcile competing and disappointing results reported to date on the utility of FSC to family firm performance. Our findings show that specific dimensions of FSC can be double-edged, exhibiting characteristics associated with a too much of a good thing effect. We urge scholars of family business strategy to expand the theoretical and empirical development of FSC and its effects on other important aspects of family business. 


\section{REFERENCES}

Adams III, A.F., Manners Jr, G.E., Astrachan, J.H., \& Mazzola, P. (2004). The importance of integrated goal setting: The application of cost-of-capital concepts to private firms. Family Business Review, 17(4), 287-302.

Adler, P.S. \& Kwon, S.W. (2002). Social capital: prospects for a new concept. Academy of Management Review, 27, 17-40.

Ahuja, G. (2000). Collaboration networks, structural holes, and innovation: A longitudinal study. Administrative Science Quarterly, 45, 425-455.

Arregle, J., Hitt, M.A., Sirmon, D.G., \& Very, P., (2007). The development of organizational social capital: attributes of family firms. Journal of Management Studies, 44(1), 73-95.

Astrachan, C.B., Patel, V.K., \& Wanzenried, G. (2014). A comparative study of CB-SEM and PLS-SEM for theory development in family firm research. Journal of Family Business Strategy, 5(1), 116128.

Birley, S. (2001). Owner-manager attitudes to family and business issues: A 16 country study. Entrepreneurship Theory and Practice, 25, 63-76.

Blanco-Mazagatos, V., de Quevedo-Puente, E., \& Castrillo, L. A. (2007). The trade-off between financial resources and agency costs in the family business: An exploratory study. Family Business Review, 20(3), 199-213.

Bubolz, M.M. (2001). Family as source, user, and builder of social capital. The Journal of SocioEconomics, 30, 129-131.

Burt, R.S. (1999). The social capital of opinion leaders. Annals of the American Academy of Political and Social Science, 566, 37-54.

Cai, L., Hughes, M., \& Yin, M. (2014). The relationship between resource acquisition methods and firm performance in Chinese new ventures: The intermediate effect of learning capability. Journal of Small Business Management, 52(3), 365-389. 
Carney, M. (2005). Corporate governance and competitive advantage in family-controlled firms. Entrepreneurship Theory and Practice, 29(3), 249-265.

Carr, J.C., Cole, M.S., Ring, J.K., \& Blettner, D.P. (2011). A measure of variations in internal social capital among family firms. Entrepreneurship Theory and Practice, 35(6), 1207-1227.

Casillas Bueno, J., López Fernández, M., Meroño Cerdán, Á., Pons Vigués, A., Baiges Giménez, R. (2015). La Empresa familiar en España. Madrid: Instituto de la Empresa Familiar (Family Firm Institute, FFI). Retrieved from: http://www.iefamiliar.com

Cesinger, B., Hughes, M., Mensching, H., Bouncken, R., Fredrich, V., \& Kraus, S. (2016). A socioemotional wealth perspective on how collaboration intensity, trust, and international market knowledge affect family firms' multinationality. Journal of World Business, 51(4), 586-599.

Chatman, J.A. \& Flynn, F.J. (2001). The influence of demographic heterogeneity on the emergence and consequences of cooperative norms in work teams. Academy of Management Journal, 44, 956974.

Chirico, F. \& Salvato, C. (2008). Knowledge integration and dynamic organizational adaptation in family firms. Family Business Review, 21(2), 169-181.

Chrisman, J.J., Chua, J.H., \& Kellermanns, F. (2009). Priorities, resource stocks, and performance in family and nonfamily firms. Entrepreneurship Theory \& Practice, 33(3), 739-760.

Claver, E., Rienda, L., \& Quer, D. (2009). Family firms' international commitment: The influence of family-related factors. Family Business Review, 22(2), 125-135.

Coleman, J.S. (1988). Social capital in the creation of human capital. American Journal of Sociology, 94, 95-120.

Coleman, J.S. (1990). Foundations of Social Theory. Cambridge, MA: Harvard University Press.

Cruz, C.C., Gómez-Mejia, L.R., \& Becerra, M. (2010). Perceptions of benevolence and the design of agency contracts: CEO-TMT relationships in family firms. Academy of Management Journal, 53(1), 69-89. 
Danes, S.M. \& Stafford, K. (2011). Family social capital as family business resilience capacity. In R.L. Sorenson (2011). Family Business and Social Capital. Edward Elgar Publishing, Inc.

Debicki, B. J., Kellermanns, F. W., Chrisman, J. J., Pearson, A. W., \& Spencer, B. A. (2016). Development of a socioemotional wealth importance (SEWi) scale for family firm research. Journal of Family Business Strategy, 7(1), 47-57.

Edmondson, A.C., \& Harvey, J.-F. (2018). Cross-boundary teaming for innovation: Integrating research on teams and knowledge in organizations. Human Resource Management Review, 28(4), 347360.

FIAB Economic Report (2017). Federación Española de Industrias de la Alimentación y Bebidas. http://fiab.es/es/archivos/documentos/INFORME_ECONOMICO_FIAB_2017.pdf

Gómez-Mejía, L.R., Haynes, K.T., Núñez-Nickel, M., Jacobson, K.J.L., \& Moyano-Fuentes, H. (2007). Socioemotional wealth and business risk in family-controlled firms: Evidence from Spanish olive oil mills. Administrative Science Quarterly, 52(1), 106-137.

Granovetter, M.S. (1973). The strength of weak ties. American Journal of Sociology, 78, 1360-1380.

Habbershon, T.G., Williams, M., \& MacMillan, I.C. (2003). A unified systems perspective of family firm performance. Journal of Business Venturing 18, 451-465.

Hair Jr., J.F., Black, W.C., Babin, B.J., \& Anderson, R.E. (2010). Multivariate Data Analysis. Upper Saddle River, NJ: Prentice Hall.

Hansen, M.T. (1999). The search-transfer problem: The role of weak ties in sharing knowledge across organization subunits. Administrative Science Quarterly, 44, 82-111.

Hauck, J., Suess-Reyes, J., Beck, S., Prügl, R., \& Frank, H. (2016). Measuring socioemotional wealth in family-owned and-managed firms: A validation and short form of the FIBER Scale. Journal of Family Business Strategy, 7(3), 133-148.

Herrero, I. (2018). How familial is Family Social Capital? Analysing bonding social capital in family and nonfamily firms. Family Business Review (in press, 2018); DOI: https://doi.org/10.1177/0894486518784 
Hitt, M.A., Lee, H., \& Yucel, E. (2002). The importance of social capital to the management of multinational enterprises: Relational networks among Asian and western firms. Asia Pacific Journal of Management, 19, 353-372.

Hoffman, J., Hoelscher, M., \& Sorenson, R., (2006). Achieving sustained competitive advantage: a family capital theory. Family Business Review, 19(2), 135-145.

Hu, L. T., \& Bentler, P. M. (1999). Cutoff criteria for fit indexes in covariance structure analysis:

Conventional criteria versus new alternatives. Structural Equation Modeling: A Multidisciplinary Journal, 6(1), 1-55.

Hughes, M., \& Perrons, R. (2011). Shaping and re-shaping social capital in buyer-supplier relationships. Journal of Business Research, 64(2), 164-171.

Hughes, M., Filser, M., Harms, R., Kraus, S., Chang, M.-L., \& Cheng, C.-F. (2018). Family firm configurations for high performance: The role of entrepreneurship and ambidexterity. British Journal of Management, 29(4), 595-612.

Hughes, M., Morgan, R.E., Ireland, R.D., \& Hughes, P. (2014). Social capital and learning from network relationships: A problem of absorptive capacity. Strategic Entrepreneurship Journal, 8(3), 214233.

Jack, S.L. (2005). The role, use and activation of strong and weak network ties: A qualitative analysis. Journal of Management Studies, 42, 1233-1259.

Kleinbaum, D.G., Kupper, L.L., Muller, K.E. Applied Regression Analysis and Other Multivariables Methods. PWS-KENT Publishing Company. 1988.

Kostova, T. \& Roth, K. (2003). Social capital in multinational corporations and the micro-macro models of its formation. Academy of Management Review, 28, 297-317.

Leana, C.R. \& Van Buren, H.J. (1999). Organizational social capital and employment practices. Academy of Management Review, 24, 538-555.

Levin, D. \& Cross, R. (2004). The strong and weak ties you can trust: The mediating role of trust in effective knowledge transfer. Management Science, 50(11), 1477-1490 
Lind, J. T., \& Mehlum, H. (2010). With or without U? The appropriate test for a U-shaped relationship. Oxford Bulletin of Economics and Statistics, 72(1), 109-118.

Ling, Y. \& Kellermanns, F.W. (2010). The effects of family firm specific diversity: The moderating role of information exchange frequency. Journal of Management Studies, 47(2), 332-344.

Long, R.G. (2011). Commentary: Social exchange in building, modeling, and managing family social capital. Entrepreneurship Theory and Practice, 35, 1229-1234.

Marrone, J.A. (2010). Team boundary spanning: A multilevel review of past research and proposals for the future. Journal of Management, 36(4), 911-940.

McEvily, B. \& Zaheer, A. (1999). Bridging ties: a source of firm heterogeneity in competitive capabilities. Strategic Management Journal, 20(12), 1133-1156.

Memili, E., Eddleston, K.A., Kellermanns, F.W., Zellweger, T.M., \& Barnett, T. (2010). The critical path to family firm success through entrepreneurial risk taking and image. Journal of Family Business Strategy, 1(4), 200-209.

Ministerio de Agricultura, Pesca, Alimentación y Medio Ambiente (2018). http://www.mapama.gob.es/es/alimentacion/temas/industria-agroalimentaria/marco-estrategico/

Molina-Morales, X. \& Martínez-Fernández, M.T. (2009). Too much love in the neighborhood can hurt: How an excess of intensity and trust in relationships may produce negative effects on firms. Strategic Management Journal, 30, 1013-1023.

Molly, V., Laveren, E., \& Deloof, M., (2010). Family business succession and its impact on financial structure and performance. Family Business Review, 23(2), 131-147.

Nahapiet, J. \& Ghoshal, S. (1998). Social capital, intellectual capital, and the organizational advantage. Academy of Management Review, 23, 242-266.

Patel, P.C. \& Fiet, J.O. (2011). Knowledge combination and the potential advantages of family firms in searching for opportunities. Entrepreneurship Theory and Practice, 35(6), 1179-1197.

Pearson, A.W., Carr, J.C., \& Shaw, J.C. (2008). Toward a theory of familiness: A social capital perspective. Entrepreneurship Theory and Practice, 32(6), 949-969. 
Pierce, J. \& Aguinis, H. (2013). The too-much-of-a-good-thing effect in management. Journal of Management, 39(2), 313-338.

Portes, A. (1998). Social capital: its origins and applications in modern sociology. Annual Review of Sociology, 24, 1-24

Powell, W.W. \& Smith-Doerr, L. (1994). Networks and economic life. In N.J. Smelser \& R. Swedberg (eds.), The Handbook of Economic Sociology (pp. 368-402). Princeton, NJ: Princeton University Press.

Sirmon, D.G. \& Hitt, M.A. (2003). Managing resources: Linking unique resources, management and wealth creation in family firms. Entrepreneurship Theory and Practice, 27(4), 339-358.

Sirmon, D.G., Hitt, M.A., \& Ireland, R.D. (2007). Managing firm resources in dynamic environments to create value: Looking inside the black box. Academy of Management Review, 32(1), 273-292.

Sorenson, R.L. \& Bierman, L. (2009). Family capital, family business, and free enterprise. Family Business Review, 22(4), 193-195.

Sorenson, R.L., Goodpaster, K.E., Hedberg, P.R. \& Yu, A., (2009). The family point of view, family social capital, and firm performance. An exploratory test. Family Business Review, 22(3), 239253.

Stam, W. \& Elfring, T. (2008). Entrepreneurial orientation and new venture performance: The moderating role of intra- and extraindustry social capital, Academy of Management Journal, 51(1), 97-111.

Stanley, L., Kellermanns, F.W., \& Zellweger, T.M. (2017). Latent profile analysis: Understanding family firm profiles. Family Business Review, 30(1), 84-102.

Suddaby, R. (2010). Editor's comments: Concept clarity in theories of management and organizations. Academy of Management Review, 35(3), 346-357.

Tsai, W. (2001). Knowledge transfer in intraorganizational networks: effect of network position and absorptive capacity on business innovation and performance. Academy of Management Journal, 44, 996-1004. 
Tushman, M.L., \& Scanlan, T.J. (1981). Boundary spanning individuals: Their role in information transfer and their antecedents. Academy of Management Journal, 24(2), 289-305.

Uzzi, B. (1996). The sources and consequences of embeddedness for the economic performance of organizations: The network effect. American Sociological Review, 61(4), 674-698.

Vedres, B., \& Stark, D. (2010). Structural folds: Generative disruption in overlapping groups. American Journal of Sociology, 115(4), 1150-1190.

Westhead, P. \& Howorth, C., (2006). Ownership and management issues associated with family firm performance and company objectives. Family Business Review, 19(4), 301-316.

Zahra, S.A. (2010). Harvesting family firms' organizational social capital: A relational perspective. Journal of Management Studies, 47, 345-366.

Zamudio, C., Anokhin, S., \& Kellermanns F.W. (2014). Network analysis: A concise review and suggestions for family business research. Journal of Family Business Strategy, 5, 63-71. 


\section{Table 1. Descriptive statistics}

\begin{tabular}{|c|c|c|c|c|c|c|c|c|c|c|c|c|c|c|c|}
\hline & Variable & Minimum & Maximum & Mean & St Dev. & 1 & 2 & 3 & 4 & 5 & 6 & 7 & 8 & 9 & 10 \\
\hline 1 & Firm age & 3 & 166 & 26.30 & 17.980 & 1 & & & & & & & & & \\
\hline 2 & Family management & 0 & 1 & .96 & .203 & -.017 & 1 & & & & & & & & \\
\hline 3 & Employees (firm size) & 10 & 850 & 40.25 & 82.102 & $.200^{*}$ & $-.155^{*}$ & 1 & & & & & & & \\
\hline 4 & Family involvement & 1 & 15 & 4.28 & 2.218 & .063 & .095 & $.156^{*}$ & 1 & & & & & & \\
\hline 5 & Generations & 1 & 2 & 1.29 & .454 & -.113 & -.066 & .001 & $.256^{* *}$ & 1 & & & & & \\
\hline 6 & OSC & 2.20 & 5.00 & 4.283 & .607 & .095 & .059 & .082 & $.158^{*}$ & . 145 & 1 & & & & \\
\hline 7 & Str. Dim. of FSC & 2.50 & 5.00 & 4.638 & .545 & -.041 & .082 & -.062 & -.002 & .031 & $.362^{* *}$ & 1 & & & \\
\hline 8 & Rel. Dim. of FSC & 1.25 & 5.00 & 4.652 & .663 & -.140 & .152 & -.097 & -.062 & -.023 & $.340^{* *}$ & $.645^{* *}$ & 1 & & \\
\hline 9 & Cogn. Dim. of FSC & 1.75 & 5.00 & 4.558 & .649 & -.051 & .113 & -.093 & -.003 & .016 & $.368^{* *}$ & $.624^{* *}$ & $.796^{* *}$ & 1 & \\
\hline & Return on Equity (ROE) & -1.35 & .76 & .06 & .51 & -.042 & $-.315^{* *}$ & $.311^{* *}$ & .014 & .026 & .096 & .084 & $.166^{*}$ & .148 & 1 \\
\hline
\end{tabular}


Table 2. Results of the hierarchical regression analyses (dependent variable: ROE)

\begin{tabular}{|c|c|c|c|c|c|c|c|c|c|c|c|c|c|c|c|c|c|c|}
\hline & Coeff. & $\mathrm{t}$ & Sig. & Coeff. & $\mathrm{t}$ & Sig. & Coeff. & $\mathrm{t}$ & Sig. & Coeff. & $\mathrm{t}$ & Sig. & Coeff. & $\mathrm{t}$ & Sig. & Coeff. & $\mathrm{t}$ & Sig. \\
\hline (Constant) & & 3.177 & .002 & & 3.235 & .001 & & 3.625 & .000 & & 3.662 & .000 & & 4.381 & .000 & & 4.415 & .000 \\
\hline Firm age & -.116 & -1.557 & .121 & -.099 & -1.344 & .181 & -.084 & -1.155 & .250 & -.071 & -.991 & .323 & -.030 & -.382 & .703 & -.038 & -.492 & .624 \\
\hline Family management & -.280 & -3.792 & .000 & -.290 & -3.960 & .000 & -.301 & -4.192 & .000 & -.280 & -3.896 & .000 & .279 & 3.740 & .000 & .281 & 3.750 & .000 \\
\hline Employees & .283 & 3.747 & .000 & .296 & 3.950 & .000 & .261 & 3.505 & .001 & .243 & 3.259 & .001 & .023 & .320 & .749 & .016 & .224 & .823 \\
\hline Family involvement & -.008 & -.110 & .912 & .005 & .070 & .944 & -.007 & -.093 & .926 & -.004 & -.059 & .953 & -.306 & -4.261 & .000 & -.304 & -4.230 & .000 \\
\hline Generations & -.023 & -.296 & .768 & -.010 & -.129 & .897 & .002 & .028 & .978 & -.004 & -.057 & .955 & -.131 & -1.689 & .093 & -.142 & -1.826 & .070 \\
\hline OSC & .119 & 1.614 & .108 & .028 & .336 & .737 & .049 & .592 & .554 & .177 & 1.686 & .094 & .028 & .347 & .729 & .026 & .311 & .756 \\
\hline Structural Dim of FSC & & & & .176 & 2.125 & .035 & -.110 & -.840 & .402 & -.230 & -1.582 & .116 & & & & & & \\
\hline Structural Dim of FSC ${ }^{2}$ & & & & & & & -.340 & -2.778 & .006 & -.739 & -3.489 & .001 & & & & & & \\
\hline Relational Dim of FSC & & & & & & & & & & & & & .211 & 2.564 & .011 & & & \\
\hline Cognitive Dim of FSC & & & & & & & & & & & & & & & & .203 & 2.454 & .015 \\
\hline StrDim of FSC * OSC & & & & & & & & & & -.133 & -.657 & .512 & & & & & & \\
\hline StrDim of FSC ${ }^{2 *} O S C$ & & & & & & & & & & -.520 & -1.765 & .079 & & & & & & \\
\hline$R$-squared & & & .194 & & & .216 & & & .254 & & & .281 & & & .246 & & & .243 \\
\hline Adjusted R-square & & & .163 & & & .181 & & & .215 & & & .233 & & & .212 & & & .209 \\
\hline$R$-squared change & & & .194 & & & .023 & & & .037 & & & .027 & & & .032 & & & .029 \\
\hline Change in $F$ & & & 6.240 & & & 4.517 & & & 7.719 & & & 2.840 & & & 6.575 & & & 6.021 \\
\hline Sig. Change in F & & & .000 & & & .035 & & & .006 & & & .062 & & & .011 & & & .015 \\
\hline
\end{tabular}


Figure 1. Curvilinear relationship between the structural dimension of family social capital (FSC) and family firm performance (ROE)

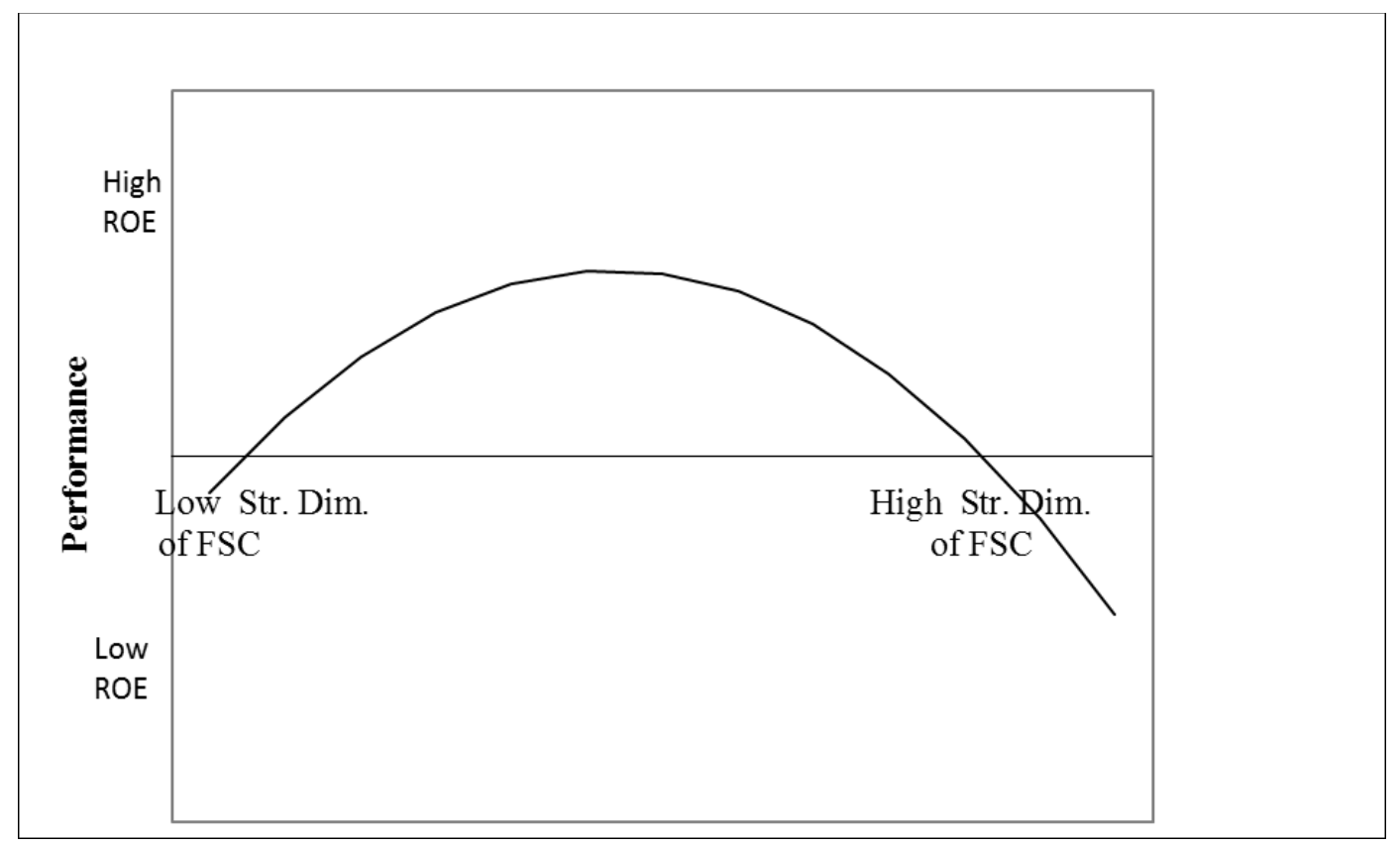


Figure 2. Moderation effect of organizational social capital (OSC) on the relationship between the structural dimension of family social capital and family firm financial performance (ROE)

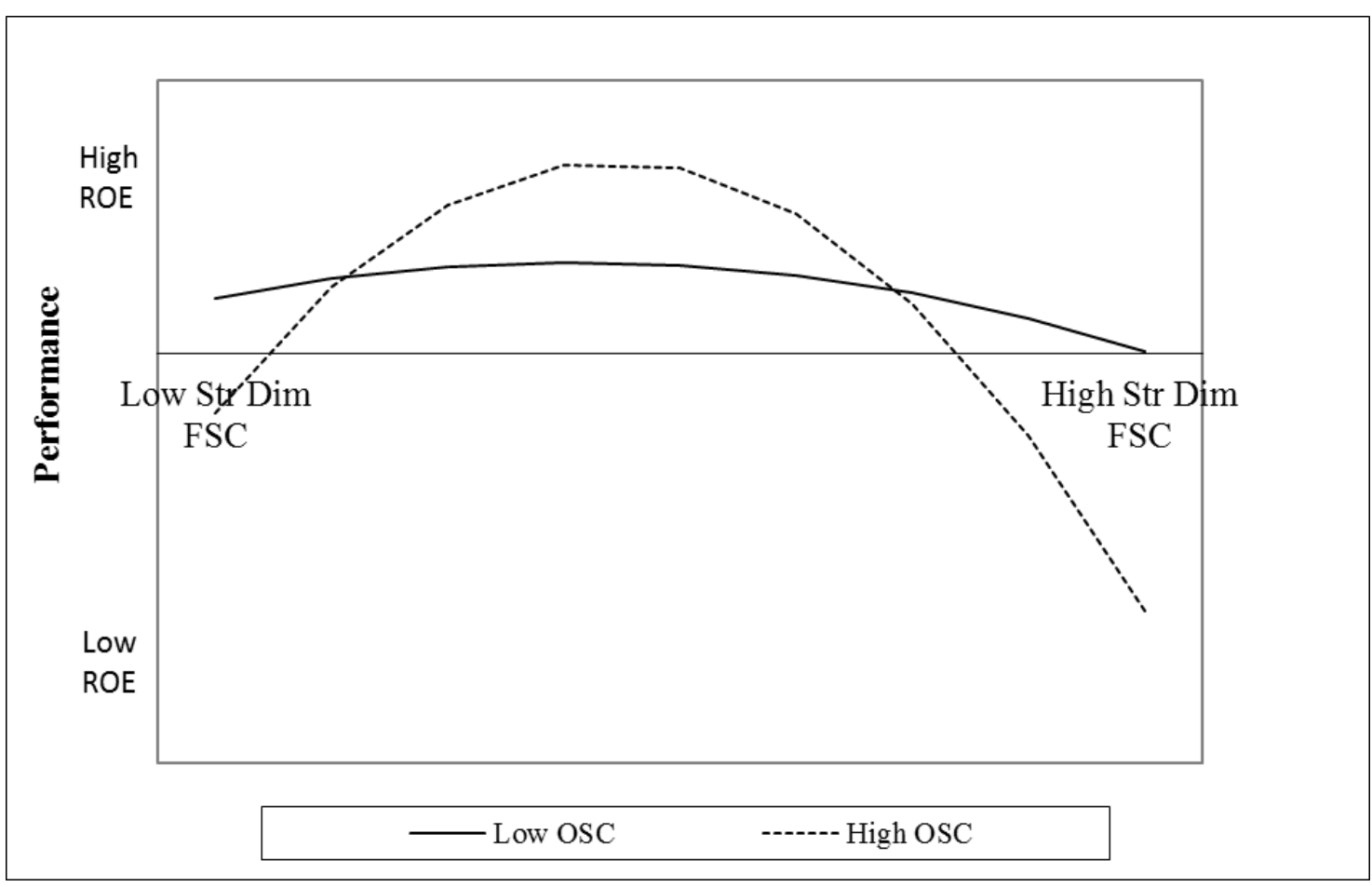




\section{APPENDIX. CFA results of key latent constructs ( $2^{\text {nd }}$-order model).}

Factor loadings

Structural dimension (Cronbach alpha=.80):

a) Family members who work in this firm engage in honest communication with one another.

b) Family members who work in this firm have no hidden agendas.

c) Family members who work in this firm willingly share information with one another.

d) Family members who work in this firm take advantage of their family relationships to share information. .602

Relational dimension (Cronbach alpha=.92).

a) Family members who work in this firm have confidence in one another.

b) Family members who work in this firm show a great deal of integrity with each other.

c) Overall, family members who work in this firm trust each other.

d) Family members who work in this firm are usually considerate of each other's feelings.

Cognitive dimension (Cronbach alpha=.89)

a) Family members who work in this firm are committed to the goals of this firm.

b) There is a common purpose shared among family members who work in this firm.

c) Family members who work in this firm view themselves as partners in charting the firm's direction.

d) Family members who work in this firm share the same vision for the future of this firm.

\section{Organizational social capital (OSC) (Cronbach alpha=.83):}

a) This company has a good reputation in its industry.

b) This company is well connected to other companies in its industry.

c) This company is well connected to other companies in other industries.

d) This company has a good reputation for supporting industry causes.

e) This company has a good reputation for fair dealings. 